\title{
Overall buckling analysis on different formed circular steel tubular columns under axial compression
}

\author{
Xi Feng Yan* \\ Dept. of Architecture and Building Engineering, Kanagawa Univ., Kanagawa 2218686, Japan
}

\begin{abstract}
This paper presents a numerical finite element model (FEM) investigation on the overall buckling behaviour of hot-rolled (HR), submerged arc welded (SAW) and high-frequency welded (HFW) steel circular columns under axial compression. Three dimensional FEM of circular hollow sections were developed using shell elements considering material nonlinearities, geometric imperfections and residual stress. The established FEM was used to simulate experimental studies conducted by past researchers. Good agreement has been found between numerical analysis and past researchers results, which has validated the reasonability of the FEM to carry out further investigation. Based on the validated FEM, numerical analysis incorporating 180 numerical generated HR, SAW and HFW steel circular columns with various section sizes and slenderness were carried out. The numerical analysis results were compared with the existing column design curves in Chinese, European and American codes. The numerical results showed that the design resistances for hot-rolled and welded steel circular columns calculated based on design curve a in both GB 50017-2003 and Eurocode 3 and the design formula in ANSI/AISC 360-2016 should be accepted. In addition, to further improve the design efficiency, new column design curves for hot-rolled and welded steel circular columns were recommended based on the expressions in GB 50017-2003 and Eurocode 3.
\end{abstract}

\section{Introduction}

Modern steel structures are not only developing to large-span, super-tall and heavy-load, but also can adapt strong earthquakes and hostile environments, such as storm, flood and atmospheric corrosion, etc.. Steel tubular structure is a new energy saving and environmental protection architectural structure, famed as the green building in $21^{\text {st }}$ century. Circular steel tubular structures are aesthetically attractive, reduce the amount of surface exposed to corrosion, and in some instances offer certain advantages in structural capacity. According to the manufacturing technique, circular steel tubes are divided into hot-rolled (HR) and welded tubes [1].

There have been a few experimental investigations reported on the overall buckling behaviour of different shaped steel circular columns, with the tests having focused mainly

* Corresponding author: ensaihou@gmail.com 
on specimens fabricated by SAW. Shi et al.[2] tested 24 SAW steel circular columns, and Zhao [3] investigated the section capacity and local buckling limits of $1350 \mathrm{MPa}$ SAW circular tubes under compression through testing 12 SAW stub circular columns. Martin et al.[4] researched local buckling behaviour of 5 bare SAW thin-walled steel circular columns and 5 filled concrete SAW thin-walled steel circular columns under axial compression, in addition, 10 bare SAW steel circular columns' local buckling behaviour under eccentric compression was also tested. $15 \mathrm{HR}$ circular specimens were tested by Georgios [5] and presented the theoretical models about plastic mechanism according to the experiments of cold-formed steel circular tubes subjected to pure bending. Recent tubular researches also extend to the new form of tubular cross sections-elliptical hollow sections [6].

However, the overall buckling capacity closely relates to the initial geometric imperfections and residual stress in the cross-section [1]. Different forming methods produce different residual stress and initial geometric imperfections [2,3]. It is considered that the design rules as presently merely reflect the member capacity for hot-rolled and welded columns under axial compression. Therefore, it is necessary to investigate the design methods for SAW, HFW and HR steel circular columns, respectively.

This paper presents a numerical finite element model (FEM) investigation on the overall buckling behaviour of hot-rolled (HR), submerged arc welded (SAW) and high-frequency welded (HFW) circular steel tubular columns under axial compression. Based on a large of parameter analysis results, and comparisons with column design curves in the Chinese code GB 50017-2003 [7], Eurocode 3 [8] and ANSI/AISC 360-2016 [9], column design curves selection guidance for all three kinds of circular steel columns is proposed, furthermore, new column curves for $345 \mathrm{MPa}$ hot-rolled and welded circular steel tubular columns in GB 50017-2003 and Eurocode 3 are recommended.

\section{Verification of finite element analysis model}

The FEM need to be verified against previously done experiments for reliability and accuracy. For this purpose, experimental study performed by Shi, et al. [2,10] has been taken into consideration. For the initial bending, the out-of-straightness of columns is measured in the length direction, defined as the maximum deviation from the straight lines connecting the points at the centroid of both column ends in the quartile following the length direction, and denoted by $v_{1}, v_{2}, v_{3}$. As well as, the eccentricity of the load is measured in the both column ends, and donated by $e_{0 t}$ (top) and $e_{0 \mathrm{~b}}$ (bottom). A comparison between the results of the numerical analysis and the experiment (Shi, et al.) is illustrated in table 1.

Table 1. Comparison between experimental and FEA results.

\begin{tabular}{|c|c|c|c|c|}
\hline \multirow[b]{2}{*}{ Specimen } & & & \multirow[b]{2}{*}{ Average of $\Delta$} \\
\hline & $N_{u, F E A}(\mathrm{kN})$ & $N_{u, E x p}(\mathrm{kN})$ & $\Delta=N_{u, F E A} / N_{u, E x p}$ & \\
\hline D420-20-1 & 2055.59 & 2094.82 & 0.9813 & \multirow{3}{*}{0.9756} \\
\hline D420-20-2 & 2139.83 & 2173.08 & 0.9847 & \\
\hline D420-20-3 & 2092.58 & 2178.10 & 0.9607 & \\
\hline D420-30-1 & 2195.71 & 2075.09 & 1.0581 & \multirow{3}{*}{1.0171} \\
\hline D420-30-2 & 2116.22 & 2094.09 & 1.0106 & \\
\hline D420-30-3 & 2006.61 & 2042.43 & 0.9825 & \\
\hline D420-40-1 & 1974.79 & 2027.24 & 0.9741 & \multirow{3}{*}{1.0121} \\
\hline D420-40-2 & 2154.00 & 2099.50 & 1.0260 & \\
\hline D420-40-3 & 2099.87 & 2026.38 & 1.0363 & \\
\hline D420-50-1 & 2024.89 & 2037.92 & 0.9936 & \\
\hline
\end{tabular}




\begin{tabular}{|l|l|l|l|l|}
\hline D420-50-2 & 1963.22 & 1997.43 & 0.9829 & \\
\hline D420-50-3 & 2216.66 & 2012.03 & 1.1017 & \\
\hline D420-60-1 & 1985.26 & 1956.83 & 1.0145 & \multirow{2}{*}{0.9818} \\
\hline D420-60-2 & 1908.99 & 1974.01 & 0.9671 & 1.0025 \\
\hline D420-60-3 & 1888.51 & 1959.65 & 0.9637 & 0.0394 \\
\hline \multicolumn{5}{|c|}{ Average } \\
\hline
\end{tabular}

Note: $N_{u, F E A}, N_{u, E x p}$-- the ultimate axial bearing capacity of FEA and experimental results of Shi, et al., respectively.

From table 1, we can have the common cognition that FEA results are agreement with the results of experiment of Shi et al.. The average ratio of FEM with experiment (Shi, et al.) is about 1.0025 , and the standard deviation is about 0.0394 . Hence, the FEM established in this investigation is validated to be accurate and reliable to simulate the overall buckling behaviour of circular steel tubular columns.

\section{Parametric analysis and design curves selection}

One purpose of this study is to obtained the overall buckling capacities of $345 \mathrm{MPa} \mathrm{HR}$, SAW and HFW circular steel columns under axial compression. According to the steel tubular design code GB/T 17395-2008 [11] and JG/T 381-2012 [12], 180 specimens with 3 different manufacturing techniques, 6 cross sections and the principle slenderness $\lambda_{\mathrm{n}}$ ranging from 0.4 to 2.2 are designed. Specific details are shown in the table 2 . The initial geometric imperfection was applied by updating the geometry based on the first-order eigenvalue buckling model. For overall geometric imperfections, $1 \%$ of the length of the specimens are adopted in all specimens as overall geometric imperfection amplitude, and not more than $10.0 \mathrm{~mm}$ [13]. Residual stress mainly is influenced by the craftsmanship and molding method of specimens. There are three different forming methods in this study, which include HR, SAW and HFW. Yan et al. [14] measured the residual stress about these three types steel circular columns and have put forward the residual stress distribution models, respectively.

Table 2. Dimensions of specimens.

\begin{tabular}{|c|c|c|c|c|}
\hline Specimens & $\begin{array}{c}\text { Outside diameter } \\
D(\mathrm{~mm})\end{array}$ & $\begin{array}{c}\text { Thickness } \\
\mathrm{t}(\mathrm{mm})\end{array}$ & $\begin{array}{l}\text { Ratios of radius } \\
\text { to thickness }\end{array}$ & $\begin{array}{c}\text { Principle slenderness } \\
\lambda_{n}\end{array}$ \\
\hline SAW-1 & 114 & 6 & 19.00 & \multirow{6}{*}{$\begin{array}{l}0.4,0.6,0.8,1.0,1.2 \\
1.4,1.6,1.8,2.0,2.2\end{array}$} \\
\hline SAW-2 & 273 & 8 & 34.13 & \\
\hline SAW-3 & 325 & 8 & 40.63 & \\
\hline SAW-4 & 406 & 8 & 50.75 & \\
\hline SAW-5 & 508 & 8 & 63.50 & \\
\hline SAW-6 & 610 & 8 & 76.25 & \\
\hline HFW-1 & 114 & 6 & 19.00 & \multirow{6}{*}{$\begin{array}{l}0.4,0.6,0.8,1.0,1.2 \\
1.4,1.6,1.8,2.0,2.2\end{array}$} \\
\hline HFW-2 & 273 & 8 & 34.13 & \\
\hline HFW-3 & 325 & 8 & 40.63 & \\
\hline HFW-4 & 406 & 8 & 50.75 & \\
\hline HFW-5 & 508 & 8 & 63.50 & \\
\hline HFW-6 & 610 & 8 & 76.25 & \\
\hline HR-1 & 114 & 6 & 19.00 & \multirow{6}{*}{$\begin{array}{c}0.4,0.6,0.8,1.0,1.2 \\
1.4,1.6,1.8,2.0,2.2\end{array}$} \\
\hline HR-2 & 273 & 8 & 34.13 & \\
\hline HR-3 & 325 & 8 & 40.63 & \\
\hline HR-4 & 406 & 9 & 45.11 & \\
\hline HR-5 & 508 & 9 & 56.44 & \\
\hline HR-6 & 610 & 9 & 67.78 & \\
\hline
\end{tabular}




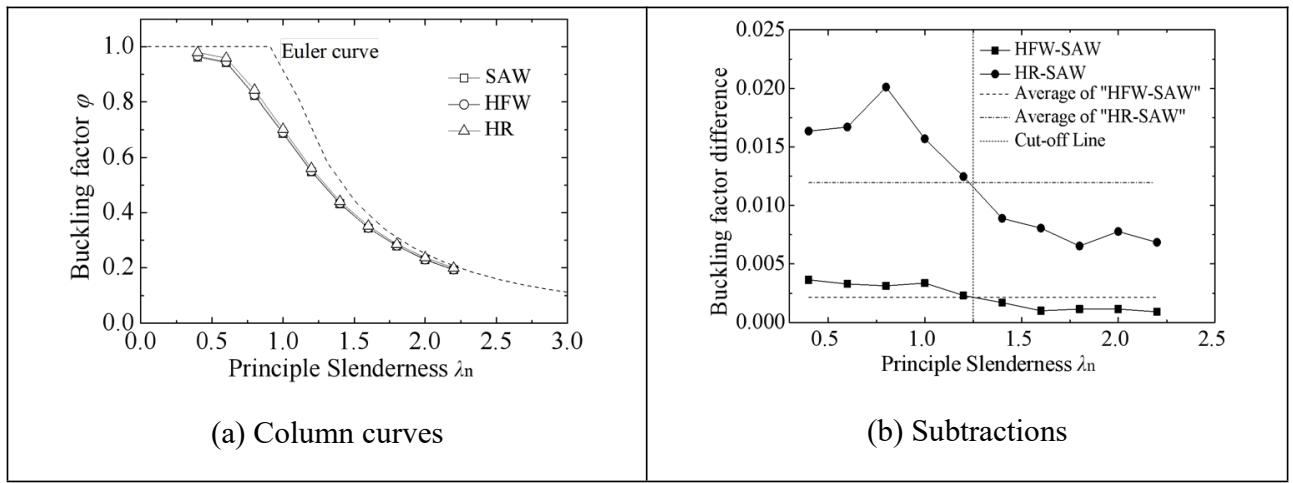

Note: SAW means submerged arc welded; HFW means high-frequency welded; HR means hot-rolled.

Fig. 1. Comparison of three different types of columns.

The FEA results of buckling factor for SAW, HFW and HR circular steel columns are shown in figure 1. According to the figure 1, the buckling factors of SAW and HFW circular steel columns are adjacent, as well as, the buckling factors of HFW circular steel columns are slightly higher than SAW circular steel columns, the buckling factors of HR circular steel columns are higher than two welded circular steel columns visibly. This suggested that the overall buckling performance of HR circular steel columns is the best; HFW circular steel columns take second place, and SAW circular steel columns are the worst. During the manufacturing technique, welding technology produces more heat than hot rolling method, besides, SAW generates higher heat relative to HFW. On account of different manufacturing techniques, there are different heat influences in the cross sections, then, different residual stress magnitude and different residual stress distribution are produced in the cross sections, and finally, there are different overall buckling behaviours for different formed circular steel columns.

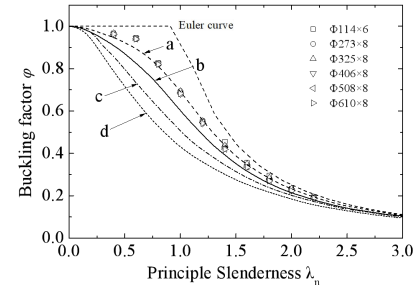

(a) SAW

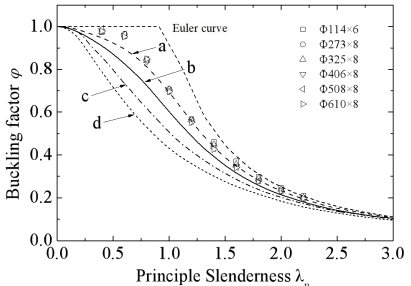

(b) HFW

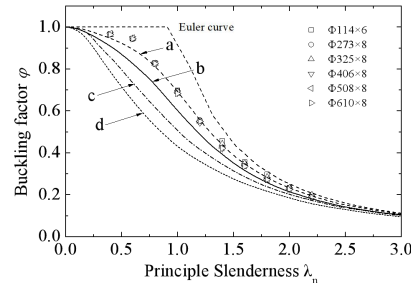

(c) HR

Fig. 2. Comparison of FEA results with GB 50017-2003.

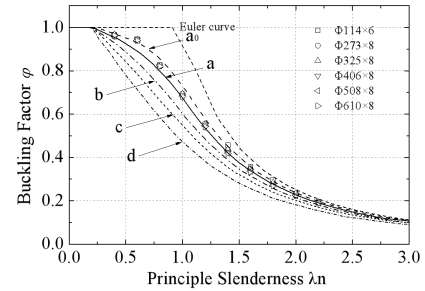

(a) SAW

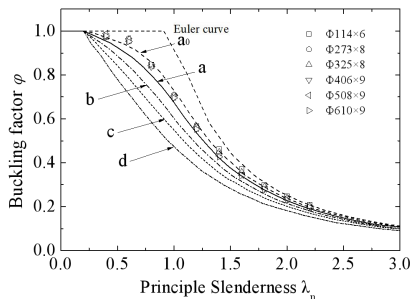

(b) HFW

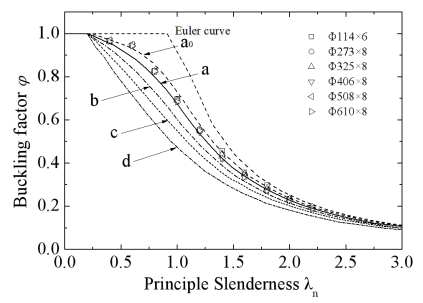

(c) HR

Fig. 3. Comparison of FEA results with Eurocode 3. 


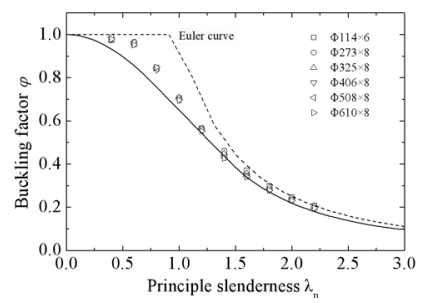

(a) SAW

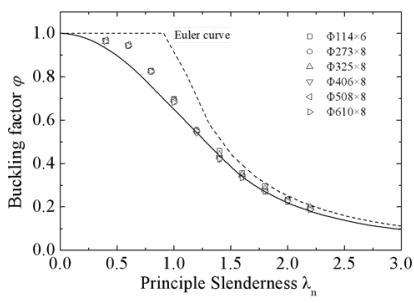

(b) HFW

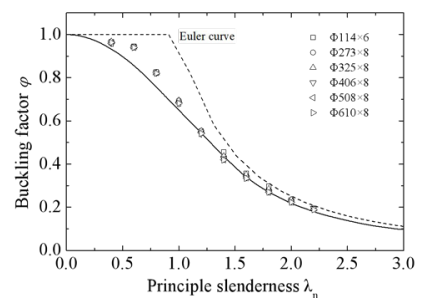

(b) HR

Fig. 4. Comparison of FEA results with ANSI/AISC 360-2016.

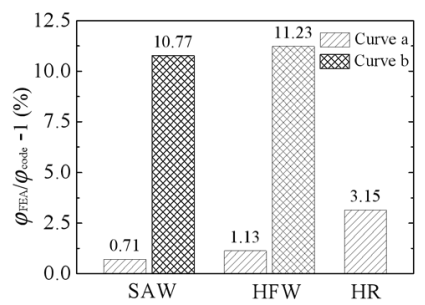

(a) GB 50017-2003

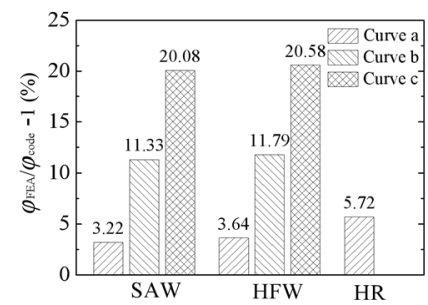

(b) Eurocode 3

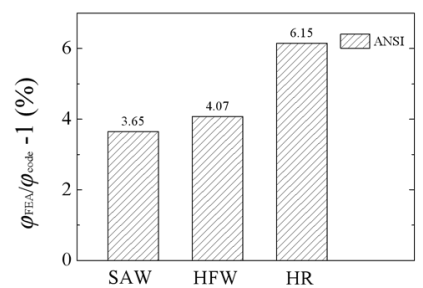

(c) ANSI/AISC 360-2016

Fig. 5. Comparison of FEA results with the current design codes.

When principle slenderness $\lambda_{\mathrm{n}} \leq 1.25, \varphi_{\mathrm{HFW}}-\varphi_{\mathrm{SAW}}$ and $\varphi_{\mathrm{HR}}-\varphi_{\mathrm{SAW}}$ exceed the average, respectively, manifests that residual stress of manufacturing technique has larger influence for circular steel columns when $\lambda_{\mathrm{n}} \leq 1.25$. According to Eurocode 3 , when $\lambda_{\mathrm{n}} \leq \sqrt{2}$, the axial compressed members are in elastic-plastic failure buckling mode, reversely, in elastic failure buckling mode. According to ANSI/AISC 360-2016 code, the column curve in ANSI/AISC 360-2016 code is reasonable for all three kinds of $345 \mathrm{MPa}$ steel circular columns when $\lambda_{n} \geq 1.2$, conversely rather safe when $\lambda_{n}<1.2$. But on the whole the column curve in ANSI/AISC 360-2016 is recommended. The FEA results demonstrate that manufacturing technique has major influence on elastic-plastic failure buckling capacity, minor effect on elastic failure buckling capacity.

For figure 5 (a) and figure 2, the column curve a is reasonable for $345 \mathrm{MPa}$ HR circular steel columns, but the column curve $b$ is not reasonable and rather safe for $345 \mathrm{MPa}$ SAW and HFW circular steel tubular columns. Therefore, the column curve a in GB 50017-2003 is suggested to design SAW, HFW and HR circular steel tubular columns.

For figure 5 (b) and figure 3, it is reasonable to choose curve a for designing HR circular steel tubular columns, however, it is rather safe to select curve c for designing SAW and HFW circular steel columns. Therefore, the column curve a in Eurocode 3 is suggested to design SAW, HFW and HR circular steel columns.

For figure 5 (c) and figure 4, the column curve in ANSI/AISC 360-2016 is recommended to design SAW, HFW and HR circular steel columns.

\section{Proposed columns design curves}

The expressions for the column curves in both GB 50017-2003 and Eurocode 3 are derived from the Perry equation, and herein are applied to determine the new column design curves. The coefficients in the expressions (i.e. the imperfection factors) are obtained through a non-leaner fitting of the results of the parametric analysis. The fitting process was based on the average level of all parametric analysis results, which is adopted in current design codes. From the section 3, there is negligible distinction of the overall buckling behaviour for SAW and HFW steel circular columns. 
Therefore, $345 \mathrm{MPa}$ circular steel columns are designed by two column curves (hotrolled and welded), and the results of hot-rolled circular steel tubular columns for the imperfection factor $\alpha_{1}, \alpha_{2}$ and $\alpha_{3}$ based on the expression in GB 50017-2003 is $\alpha_{1}=0.086$, $\alpha_{2}=0.975$ and $\alpha_{3}=0.134$, respectively. The results of welded circular steel tubular columns for the imperfection factor $\alpha_{1}, \alpha_{2}$ and $\alpha_{3}$ based on the expression in GB 50017-2003 is $\alpha_{1}=0.101, \alpha_{2}=0.969$ and $\alpha_{3}=0.165$, respectively, the new column curves are plotted with the results of the parametric analysis in figures 6. (a) and (b). Based on the expression in Eurocode 3, the fitting result about hot-rolled and welded circular steel tubular columns for the imperfection factor is 0.138 and 0.164 , respectively, and the corresponding new curve is plotted in figures 6. (c) and (d), respectively.

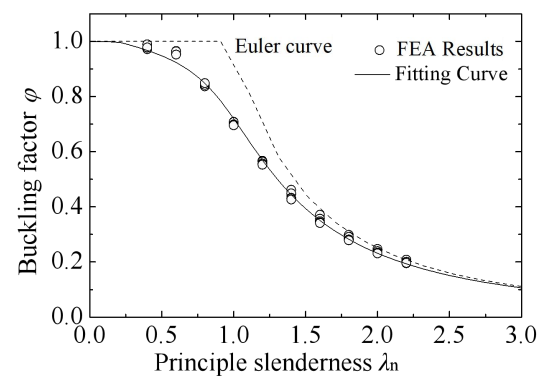

(a) HR in GB 50017-2003

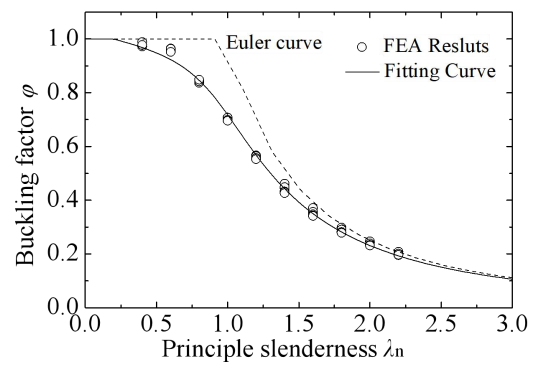

(c) HR in Eurocode 3

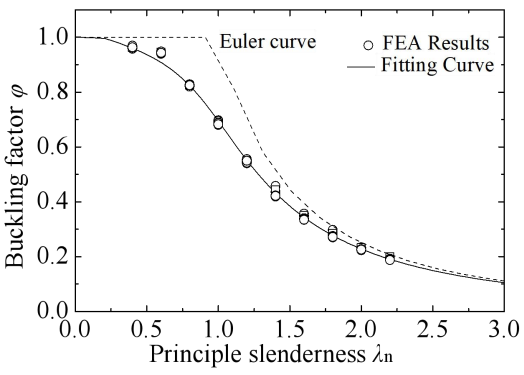

(b) Welded in GB 50017-2003

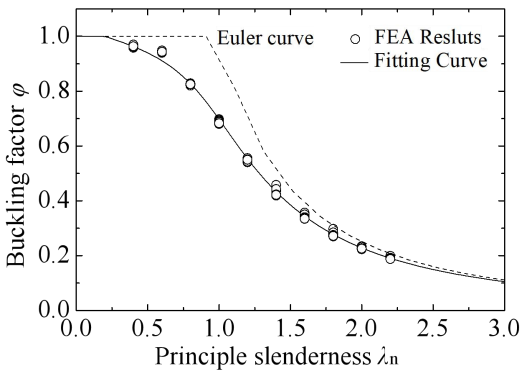

(d) Welded in Eurocode 3

Fig. 6. Proposed curves in GB 50017-2003 and Eurocode 3.

\section{Conclusion}

This paper presents a numerical finite element model (FEM) investigation on the overall buckling behaviour of hot-rolled (HR), submerged arc welded (SAW) and high-frequency welded (HFW) circular steel tubular columns under axial compression. Based on comparisons of FEA results and the current design codes, the main conclusions are as follows:

(1) Aiming at the overall buckling behavior of $345 \mathrm{MPa}$ HR, SAW and HFW circular steel tubular columns, SAW is the worst, HR is the best, and HFW is between SAW and HR. When principle slenderness $\lambda_{\mathrm{n}} \leq 1.25$, manufacturing technique has a bigger influence in the overall buckling behavior than $\lambda_{\mathrm{n}}>1.25$. Therefore, the manufacturing technique mainly influences the overall buckling performance in elastic-plastic failure stage;

(2) Compared with the experimental results, the FEM established in this investigation is validated to be accurate and reliable to simulate the overall buckling behavior of steel circular columns;

(3) Based on comparisons of the FEA results and the current design codes, the column curve a in GB 50017-2003 and Eurocode 3 is suggested to design SAW, HFW and HR 
circular steel tubular columns.

(4) New column curves are proposed in this paper to predict the buckling behavior of circular steel tubular columns. The fitting imperfection factors based on the expression in GB 50017-2003 are $\alpha_{1}=0.086, \alpha_{2}=0.975, \alpha_{3}=0.134$ and $\alpha_{1}=0.101$, $\alpha_{2}=0.969, \alpha_{3}=0.165$ for HR and welded circular steel columns, respectively, and the corresponding factor based on expression in Eurocode 3 is $\alpha=0.138$ and $\alpha=0.164$ for HR and welded circular steel columns, respectively.

\section{References}

1. Kulak, Geoffrey L. Tubular members-large and small. Engineering Structures 1996; 18(10): 745-751.

2. Shi G, Jiang X, Zhou WJ. Experimental study on column buckling of 420MPa high strength steel welded circular tubes. Journal of Constructional Steel Research 2014; 100: 71-81.

3. Zhao XL. Section capacity of very high strength (VHS) circular tubes under compression [J]. Thin-Walled Structures 2000; 37(3): 223-240.

4. O'Shea, Martin D, Bridge, Russell Q. Local buckling of Thin-walled Circular Steel Sections With or Without Internal Restraint [J]. Journal of Constructional Steel Research 1997; 41(2-3): 137-157.

5. Elchalakani M, Zhao XL, Grzebieta RH. Plastic mechanism analysis of circular tubes under pure bending. International Journal of Mechanical Sciences 2002; 44(6): 11171143.

6. Chan, T. M., and Gardner, L. Flexural Buckling of Elliptical Hollow Section Columns [J]. Journal of Structural Engineering ASCE 2009; 135(5): 543-557.

7. Code for design of steel structures. GB 50017-2003; China; 2003.

8. Eurcode 3. Design of steel structures. Part 1-1: General rules and rules for Buildings. BS EN 1993-1-1; 2005.

9. ANSI/AISC 360-16. Specification for Structure Steel Buildings. Chicago: AISC, 2016.

10. Shi G, Jiang X, Zhou WJ, et al. Experimental study on the buckling behavior of Q420 high strength steel welded tubes under axial compression and design methods. Engineering Mechanics 2015; 32(02):64-73.

11. GB/T 17395 - 2008. Dimensions, shapes, masses and tolerances of seamless steel tubes. Beijing: China Standards Press; 2008.

12. JG/T 381-2012. Cold-formed welded circular tubes for building structures. 2012.

13. GB 50205-2001. Code for acceptance of construction quality of steel structures.2001.

14. Yang JF, Yan XF, Liu HF et al.. Detection and Analysis on Residual Stress Distribution Induced by the Processing Method of Circular Tubes. Engineering Mechanics 2017; 9:202-210. 